\title{
Institutionalized Misogyny: A Call to Action
}

\author{
Nora V. Becker, MD, PhD ${ }^{1,2} \odot$, Nicole M. Hadeed, $M D^{7}$, and Allison L. Ruff, $M D^{l}$
}

\begin{abstract}
${ }^{1}$ Division of General Medicine, University of Michigan Medical School, University of Michigan, 2800 Plymouth Rd, Building 16, Room 430W, Ann Arbor, USA; ${ }^{2}$ Institute for Healthcare Policy and Innovation, University of Michigan, Ann Arbor, USA 2021@ Society of General Internal Medicine, 2021
\end{abstract}

J Gen Intern Med 37(6):1537-39

DOI: $10.1007 / \mathrm{s} 11606-021-07266-7$

(C) Society of General Internal Medicine 2021

Gender disparities in academic medicine are widely described. Many have posited the role of subtler manifestations of bias, and the term microaggression has become mainstream, describing subtle verbal and nonverbal behaviors that are brief, commonplace, and borne of unconscious bias. Microaggressions communicate negative attitudes towards a marginalized group and are suspected to have cumulative psychological impacts that ultimately erode wellbeing, mental health, self-confidence, and performance. ${ }^{1}$

Microaggressions in medicine and medical education have been recognized across multiple dimensions of identity, including gender. The literature on microaggressions defines several types: microassaults, microinsults, microinvalidation, and environmental microaggressions. ${ }^{2}$ However, we propose a category of microaggressions that has not yet been addressed - those we refer to here as institutionalized misogyny. Interventions have been developed for verbal and situational microaggressions in the workplace, ${ }^{3,4}$ but what about when those microaggressions occur from the very tools we use to care for patients? To our knowledge, there is no systematic examination of these types of experiences in the literature, although we have encountered several examples during our own training and careers.

Consider the NIH Stroke Scale, a well-studied and validated diagnostic tool for stroke, which includes a figure used to evaluate language and comprehension (Fig. 1). This image depicts a woman at the sink washing dishes while her children steal cookies from the cookie jar. She wears a dress, an apron, and high heels. What is the effect of that description on the patient's approach to the female members of the team? When the image of a "typical" situation is that of a woman as a homemaker, how do we imagine a female medical student will feel walking away from this encounter?

Assume that medical student then moves on to her surgery rotation, where she reads in Dr. Pestana's Surgery Notes that, "Cushing [Syndrome] can be identified...by looking at the picture of a lovely young woman next to a picture of a 'monster' who is the same lady a couple of years later.... Suppression at low dosage rules out the disease (she is just

Received: 25 August 2021

Accepted: 29 October 2021

Published online January 17, 2022 a fat hairy lady)." ${ }^{5}$ Here, the actual textbook not-so-subtly reminds women their role is to be attractive and young. A required textbook for Australian medical students, Advanced Techniques in Orthopaedics, recently came under fire for photos demonstrating physical exam techniques which featured women unnecessarily dressed only in underwear, posed in a seductive way completely inappropriate for a medical encounter. ${ }^{6}$

The authors were also struck by the St. Louis Mental Status (SLUMs) examination, a validated tool for assessing cognitive function in the elderly, and the only such validated tool currently available in the public domain for clinical use. ${ }^{7}$ It features the following vignette:

Jill was a very successful stockbroker. She made a lot of money on the stock market. She then met Jack, a devastatingly handsome man. She married him and had three children. They lived in Chicago. She then stopped work and stayed at home to bring up her children. When they were teenagers, she went back to work. She and Jack lived happily ever after.

The patient is then asked several questions about the details of the story to test their ability to recall and interpret information. As three working female physicians who could reasonably be expected to administer this test to patients during our normal workday, this vignette left us feeling invalidated and disempowered. Leaving the workforce to care for children full-time is a choice many women can and do make. However, this story ignores the experiences of millions of female physicians and medical trainees who become mothers and continue to work and train to achieve their goal of a successful career in medicine. How can we expect to receive the professional support of our institutions if the default societal expectation-one perpetuated by the tools we use routinely in patient care-is the dated belief that motherhood and professional success are incompatible? These examples may seem small, and one could argue that these are simply outof-date tools that need revision. However, we would argue that the fact that these tools-which remain in daily clinical use-have never been challenged or re-examined is a major part of the problem.

Furthermore, these assumptions can bear fruit in unexpectedly dangerous ways. During the recent COVID-19 pandemic, the availability of personal protective equipment (PPE) became newly important. But PPE is constructed, by default, for men's bodies and faces, and in fact, recent data 
Fig. 1 The primary image used in the NIH Stroke Scale. Patients are asked to describe what is happening in the image to assess comprehension and language ability. Image source: Ortiz GA, Sacco RL. National Institutes of Health Stroke Scale (NIHSS). In: Wiley StatsRef: Statistics Reference Online. American Cancer Society; 2014. https://doi.org/10.1002/ 9781118445112.stat06823

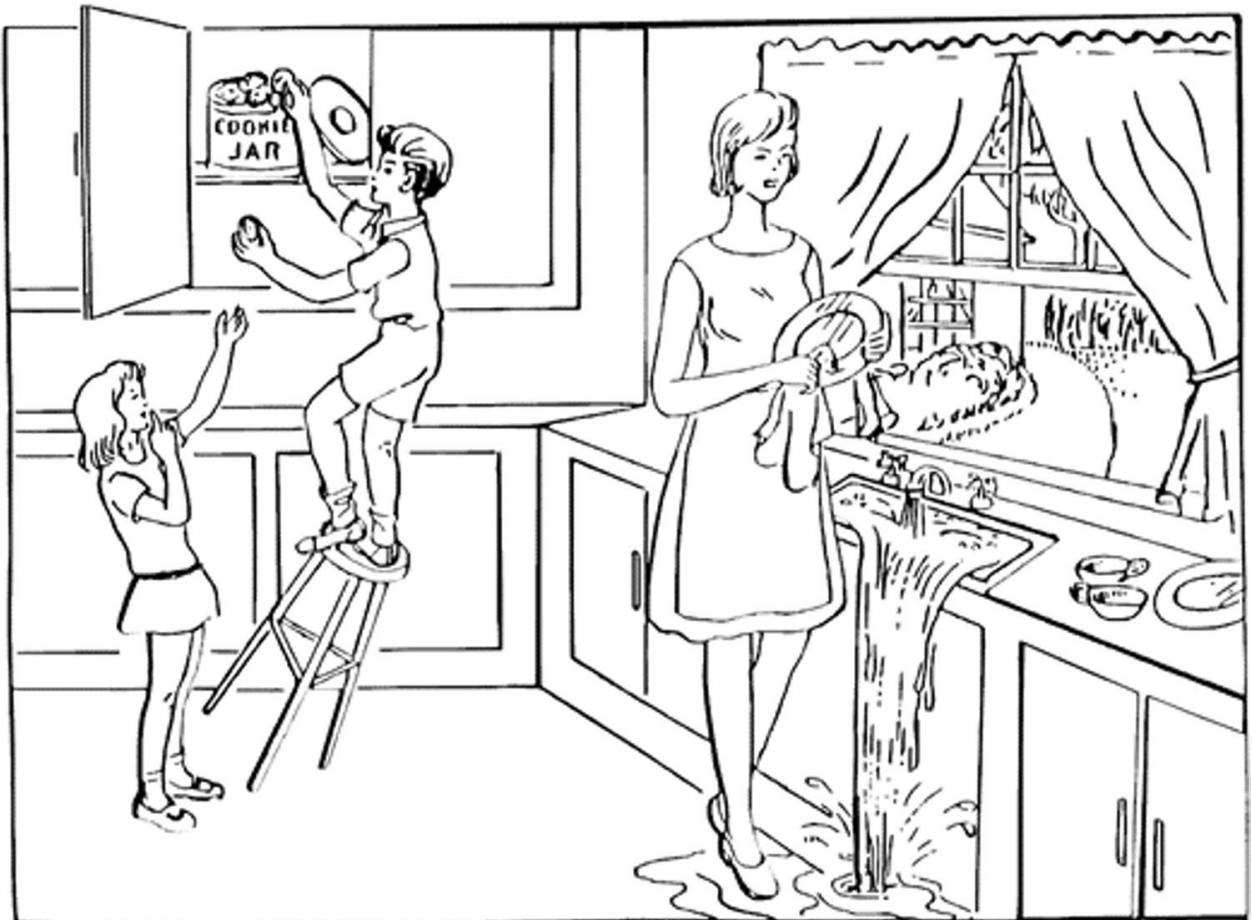

shows that women fail "fit testing," the testing that verifies that N95 masks provide adequate protection, at rates twice that of male providers. ${ }^{8}$ The design of PPE quite literally sends the message, in turn, that female bodies and faces still do not belong in the role of medical provider.

These examples of institutionalized misogyny, like other microaggressions, are perpetuated without the active participation or negative intent of any particular member of the privileged group. But the lack of intention to harm does not mean that harm is not being done. We worry about the impact these subtle messages exert on female trainees and physicians. These negative impacts may also be felt at an even greater magnitude by female physicians of color, who must handle gender-based microaggressions and structural racism simultaneously.

Our healthcare institutions need to recognize that this institutionalized misogyny exists and likely has negative consequences for female trainees. Much more research is needed to study the impacts of these types of microaggressions on female physicians and physicians-in-training. And as we develop our arsenal of responses and bystander interventions to in-person microaggressions, we need to ensure we are approaching all categories of this important issue in real time, for ourselves and our learners, including the examples we have cited here. These examples, which remain widely used, have not been critically examined in recent years; the creators of such scales, tests, and equipment need to be open to revising and changing their products in response to feedback such as ours. And the institutions that use them should be willing to demand just such a critical examination on behalf of their female staff and trainees. As a starting point, we recommend that healthcare institutions implement training for all staff using the toolkits that have been developed for person-to-person microaggressions, ${ }^{3,4}$ and that they also create a reporting mechanism by which medical trainees and physicians can report the examples of institutionalized misogyny of the type we have highlighted. Such a report should trigger an examination of the tool, equipment, or working conditions that have been reported for potential update or removal.

While researching this article, we corresponded with the only female member of the team that created the SLUMS examination. She explained that the original version of the story had involved a woman with a career outside of the home. Focus group feedback from patients was that a story featuring a woman with both children and a career was unacceptable, and so the vignette was altered. She concluded her remarks by saying:

Fifty years ago, when I was starting my education, women could be teachers, secretaries, nurses or mothers...just until they married and raised families. Those of us who decided to be scientists or engineers were viewed with suspicion...So I urge you to consider the time. It does not excuse misogyny or perceived misogyny but I hope that it does put it in context. It is your generation's chance to erase stereotypes and reach for the sun. ${ }^{9}$

Our hope is to bring attention to the subtle and institutionalized ways misogyny may harm female medical trainees and 
female physicians, and to do our part to change and improve the experience and career outcomes for future generations of female physicians.

Corresponding Author: Nora V. Becker, MD, PhD.; Division of General Medicine, University of Michigan Medical School, University of Michigan, 2800 Plymouth Rd, Building 16, Room 430W, Ann Arbor, USA (beckernv@med.umich.edu).

\section{References}

1. Montenegro RE. My Name Is Not "Interpreter." JAMA 2016;315(19):2071. https://doi.org/10.1001/jama.2016.1249

2. Torres MB, Salles A, Cochran A. Recognizing and Reacting to Micro aggressions in Medicine and Surgery. JAMA Surg. 2019;154(9):868. https://doi.org/10.1001/jamasurg.2019.1648.

3. Warner NS, Njathi-Ori CW, O'Brien EK. The GRIT (Gather, Restate, Inquire, Talk It Out) Framework for Addressing Microaggressions. JAMA Surg. 2020;155(2):178-179. https://doi.org/10.1001/jamasurg.2019. 4427.
4. Fisher HN, Chatterjee $\mathbf{P}$, Shapiro J, Katz JT, Yialamas MA. "Let's Talk About What Just Happened": a Single-Site Survey Study of a Microaggression Response Workshop for Internal Medicine Residents. J Gen Intern Med. Published online January 21, 2021. https://doi. org/10.1007/s11606-020-06576-6.

5. Pestana C. Dr. Pestana's Surgery Notes: Top 180 Vignettes of Surgical Diseases. Kaplan Publishing; 2020.

6. Harris N, Stanley D, eds. Advanced Examination Techniques in Orthopaedics. Cambridge University Press; 2005.

7. Tariq SH, Tumosa N, Chibnall JT, Perry MH, Morley JE. Comparison of the Saint Louis University mental status examination and the mini-mental state examination for detecting dementia and mild neurocognitive disorder--a pilot study. Am J Geriatr Psychiatry Off J Am Assoc Geriatr Psychiatry. 2006;14(11):900-910.doi:https:// doi.org/10.1097/01.JGP.0000221510.33817.86

8. Ascott A, Crowest P, Sausmarez E de, Khan M, Chakladar A. Respiratory personal protective equipment for healthcare workers: impact of sex differences on respirator fit test results. Br $\mathbf{J}$ Anaesth. 2021;126(1):e48-e49. https://doi.org/10.1016/j.bja. 2020.10.016.

9. Tumosa N. Email communication to authors, April 28th, 2021.

Publisher's Note Springer Nature remains neutral with regard to jurisdictional claims in published maps and institutional affiliations. 